\title{
Career hopes of dental school applicants
}

\author{
A survey of dental school applicants' career intentions and the balance with family life \\ F. M. J. Stewart, J. R. Drummond, L. Carson, G. Hoad Reddick Br Dent J 2005; 198: 713-717.
}

Purpose

To investigate the career plans of prospective dental students and how they foresee their work life balance.

Method

Applicants to Dundee and Manchester dental schools completed anonymous questionnaires when they attended for interview.

\section{Results}

The useable response rate was $94 \%(n=436)$. The majority of the respondents (91.3\%) intended working full time when they entered the workforce, with no significant variation detected between males and females. The cohort anticipated their mean salary to be just over $£ 28,000$ five years into their career, although males felt they would be earning $£ 5,000$ more than females. Individuals of Pakistani and Indian origin thought they would earn most, and Asians least.

Sixty-five per cent wanted to enter general dental practice and, of these, only $2.8 \%$ expected to work exclusively within the NHS. Fifteen per cent intended to go into the hospital dental service, with orthodontics the most popular choice of subspecialty (43.7\%), followed by oral surgery (31.1\%). Significant variation was seen between ethnic groups, with the hospital and community dental services being more popular with those who identified themselves as of non-white ethnic origin, although most still planned on entering general dental practice.

Almost half (44.5\%) would take time out of their career to concentrate on childcare when children were of pre-school age, with a further $11 \%$ taking longer. Ninety per cent of females and $70 \%$ of males anticipated taking time out, of a varying duration. Half of the respondents indicated that they felt a child would affect their career to a moderate extent.

\section{Conclusions}

The dental profession will be severely affected if both males and females take time out of their careers in the future. As well as a work force shortage, the problems of accessibility to NHS dental services will be exacerbated if fewer dentists choose to provide NHS care.

\section{IN BRIEF}

- It has been well established that work patterns of male and female dentists differ.

- 95\% of respondents felt that a postgraduate qualification would assist their career prospects.

- More than $91 \%$ considered childcare should be shared equally between both parents.

- 34\% of males and $56 \%$ of females stated they would take time out of their careers when their children were of pre-school age.

- $3 \%$ of those intending to enter general dental practice would work exclusively in the NHS.

\section{COMMENT}

Workforce planning has been the focus of much attention in the UK recently. As part of the review of likely future workforce requirements, attempts have been made to determine the impact of working patterns and career choices on the supply of workforce. ${ }^{1}$ It is evident that part-time working and extended career breaks will result in a decrease in the available workforce. Two methodological approaches exist for predicting the likely work patterns of future dental practitioners: estimates based on the working patterns of previous cohorts of practitioners, or estimates based on the stated intention of practitioners at an early point in their career. Both methods have advantages and disadvantages, however to date Stewart et al. have provided the only data based on the exploration of student intentions. The finding that stated intentions closely resemble the actual working practices of Scottish graduates followed up in cohort studies provides some validation of this method of estimating career pathways. There is a need for further research exploring the relationship between career intentions and future behaviour of dental practitioners.

Irrespective of the method used, the likely working patterns of practitioners' actual working practices and career development will be influenced by factors related both to the provision of dental services and broader societal factors. Any change in the system of remuneration may affect practitioners' decisions to work part-time or to take career breaks, as well as more general change in legislation relating to employment law (for example changes in funding of maternity and paternity leave).

Stewart et al. also explore a more subtle aspect of career choice in terms of the attitudes and values which relate to working practices. Of particular interest in this regard in the current paper are the data on students' attitudes to working parents. The students express a range of views, but it is interesting to note that over half the students said that a mother working full-time would have a negative impact on their child. These views varied across ethnic groups suggesting that working patterns of dental practitioners may be influenced not only by changes in the gender distribution of dental practitioners, but also by shifts in the ethnic and cultural composition of the dental workforce. ${ }^{2}$

This paper provides a fascinating description of the stated intention of dental undergraduates concerning their future career pathways, together with an insight into some of the attitudes and values that underpin these intentions.

J. T. Newton, Professor of Psychology as Applied to Dentistry, GKT Dental Institute, King's College London

1. NHS Education for Scotland/ISD Scotland (2004) Workforce planning for dentistry in Scotland. Available at http://www.nes.scot.nhs.uk/dosc/publications / workforce_planning.pdf (Accessed 2.11.04)

2. Bedi R, Gilthorpe M S. Ethnic and gender variations in university applicants to United Kingdom medical and dental schools. Br Dent J 2000, 189: 212-215. 